\title{
Relações entre as Capacidades Preditas de Transmissão de Touros Gir e a Produção de Leite de suas Filhas Puras e Mestiças
}

\author{
Mario Luiz Martinez ${ }^{1,2}$, Rui da Silva Verneque ${ }^{1,2}$, Roberto Luiz Teodoro ${ }^{1,2}$, José de Paula \\ Campos $^{3}$, Mauro Cruz ${ }^{4}$, Luiz Ronaldo Oliveira de Paula ${ }^{4}$
}

RESUMO - Os registros de produção de leite de 5258 lactações ao primeiro parto, provenientes de vacas puras Gir e mestiças Gir:Holandês, foram utilizados para se avaliar a relação entre a capacidade predita de transmissão (PTA) de um touro e a produção de leite de suas progênies. O modelo animal foi utilizado para se estimarem as PTAs dos touros, considerando-se apenas as filhas puras Gir, apenas as filhas mestiças e todas as filhas ao mesmo tempo. Posteriormente, estimaram-se as regressões e correlações das PTA dos touros, obtidas sob as diferentes alternativas, com as produções de leite de suas filhas puras e/ou mestiças. O coeficiente de regressão estimado das PTAs de 48 touros Gir avaliados com filhas puras sobre a produção de suas filhas mestiças foi de 0,75 , enquanto o da regressão das PTAs de 50 touros Gir avaliados com base na produção de filhas mestiças, sobre a produção de suas filhas puras, foi de 1,11 . Os coeficientes de correlação entre as PTAs dos touros e a produção de leite de suas filhas, para as diferentes alternativas, variaram de 0,05 a 0,17. As correlações de ordem entre os valores das PTA variaram de 0,34 a 0,94 , em que a menor foi observada entre as PTAs com informações das filhas mestiças e as PTAs obtidas com informações das filhas puras, e a maior, entre as PTAs obtidas pela média ponderada das PTAs obtidas com as filhas puras e mestiças com as PTAs obtidas com dados de filhas puras.

Palavras-chave: avaliação genética, correlação, gado Gir, PTA, produção de leite, regressão

\section{Relationships between Predicted Transmitting Ability of Gyr Bulls and the Milk Production of their Straightbred Gyr and Crossbred Progenies}

\begin{abstract}
Milk production records of 5,258 lactations at first calving from straightbred Gyr and crossbred Gyr:Holstein cows were used to evaluate the relationship between sire predicted transmitting ability (PTA) and the milk production of their progeny. Animal model was used to calculate the PTA using straightbred Gyr daughter only, the crossbred Gyr daughters only and all daughters at the same time. Subsequently, the PTA regressions and correlations of the sires obtained under different alternatives, with the straightbred and, or crossbred daughters production were estimated. The estimated regression coefficient of PTA of 48 Gyr bulls evaluated with straightbred Gyr daughter production on their crossbred daughters milk production was 0.75 , while the regression coefficient of PTA of $50 \mathrm{Gyr}$ bulls evaluated on crossbred daughter production on their straightbred daughters production was 1.11. The correlation coefficients between PTA of the sires and daughters milk production for the different alternatives ranged from 0.05 to 0.17 . The rank correlation among PTA ranged from 0.34 to 0.94 , were the smallest observed between PTA on crossbred daughters and PTA on straightbred Gyr daughters, and the highest, between the PTA observed by the weighed PTA means from straightbred and crossbred daughters with PTA observed with data from straightbred daughters.
\end{abstract}

Key Words: correlation, genetic evaluation, Gyr cattle, milk production, PTA, regression

\section{Introdução}

O melhoramento genético de bovinos de leite tem-se baseado, ao longo dos anos, na seleção de indivíduos que apresentam um diferencial melhorador de genética aditiva em relação aos seus pares. Este diferencial tem sido estimado, no caso dos machos, por intermédio do desempenho produtivo de suas progênies. HENDERSON (1975) descreveu mode- los lineares alternativos para avaliação genética de reprodutores. Nos países de clima temperado, esta avaliação baseia-se principalmente no desempenho das progênies puras de uma mesma raça, enquanto nos países localizados nas regiões tropicais, devido às condições ambientais, prevalecem os animais originados do cruzamento das raças locais ou zebuínas com as raças européias e as avaliações genéticas baseiam-se no desempenho desta progênie mestiça.

\footnotetext{
${ }^{1}$ Pesquisador daEMBRAPA/CNPGL-RuaEugênio do Nascimento,610-Dom Bosco, 36038-330, Juiz de Fora, MG. E.mail:martinez@cnpgl.embrapa.br

${ }^{2}$ Bolsista do CNPq.

${ }^{3}$ Assistente de Pesquisa da EMBRAPA Gado de Leite.

${ }^{4}$ Assistente de Pesquisa - Convênio EMBRAPA Gado de Leite/Associação Brasileira de Criadores de Gir Leitero (ABCGIL).
} 
Nos mestiços, o desempenho individual tem como base, além da porção aditiva, a genética não-aditiva, que não é transmitida de pai para filho. Assim, um dos problemas é como avaliar os animais para efeitos aditivos com base no desempenho de animais mestiços, de tal forma a eliminar os vieses decorrentes dos efeitos não-aditivos. A avaliação genética de indivíduos, considerando-se os efeitos não-aditivos, foi discutida por HENDERSON (1985). O uso do modelo animal na avaliação de animais cruzados tem-se intensificado nos últimos anos (ARNOLD et al., 1992). Em inúmeros trabalhos, utilizaram-se os procedimentos do modelo animal sob a metodologia dos modelos mistos, sendo abundantes na literatura os trabalhos com bovinos de corte (GREGORY et al., 1994, 1995a,b; MEYER et al., 1994; RODRÍGUEZALMEIDA et al., 1995; e VAN VLECK e CUNDIFF, 1994). Os raros trabalhos com gado de leite são de DIM (1974), que reportou ordenação similar de touros, quando as avaliações genéticas dos mesmos basearam-se nos desempenhos produtivos de filhas puras ou mestiças, e de RUVUNA e McDANIEL (1983), que estudaram a relação entre os valores genéticos de, respectivamente, 97 e 95 touros da raça Holandesa e Suíça Parda e o desempenho produtivo de suas 328 fillhas mestiças. RUVUNA e McDANIEL (1983) concluíram que a seleção de touros com base no teste de progênie de suas filhas puras seria efetiva para melhorar a produção de leite das progênies mestiças. Nesse trabalho, a média das estimativas das regressões do desempenho produtivo ao primeiro parto de suas filhas mestiças sobre as capacidades preditas de transmissão dos touros de ambas as raças foi de 0,99 .

A eficiência da seleção em animais de raças puras, para melhorar o desempenho dos mestiços, depende basicamente do tipo de ação dos genes. Se ela for principalmente aditiva, haverá alta correlação entre o desempenho das filhas puras e mestiças de um mesmo touro. Conseqüentemente, seleção com base em animais puros melhorará os animais mestiços. Em contrapartida, baixa correlação genética entre o desempenho dos puros e mestiços pode sugerir importância relativa maior dos efeitos nãoaditivos dos genes. VAN DER WERF e BOER (1989) simularam efeitos genéticos não-aditivos para produção de leite e estudaram a influência destes efeitos sobre as estimativas dos valores genéticos dos touros. Os autores concluíram que as estimativas dos valores genéticos dos touros foram viesadas, quando nos modelos de avaliação não se incluíram os efeitos não-aditivos. Da mesma forma, as estimativas das variâncias entre touros também foram afetadas. Todavia, quando as avaliações foram realizadas considerando-se touro dentro do grupo genético de vacas, as estimativas dos valores genéticos dos reprodutores foram obtidas sem viés. Semelhantemente, quando os efeitos genéticos nãoaditivos foram incluídos no modelo, as estimativas obtidas foram praticamente iguais aos parâmetros genéticos simulados, indicando a necessidade de se considerarem estes efeitos nas avaliações genéticas de reprodutores, quando as mesmas se baseram no desempenho de progênies mestiças.

Considerando-se a pouca disponibilidade de animais zebuínos puros, explorados para produção de leite no Brasil, e, conseqüentemente, a baixa disponibilidade de touros, com capacidade genética comprovada para a melhoria dos rebanhos de animais puros e seus mestiços, torna-se de grande importância avaliar a relação entre a seleção de reprodutores avaliados com base em suas capacidades preditas de transmissão, estimadas utilizando-se a performance de animais cruzados, e o desempenho produtivo de suas progênies tanto mestiças como puras. Assim, o objetivo deste trabalho foi estudar a relação entre as capacidades preditas de transmissão dos touros, quando os mesmos são avaliados pelas suas progênies puras e/ou mestiças, e as produções de leite de suas progênies puras e mestiças.

\section{Material e Métodos}

Os dados utilizados neste trabalho são provenientes dos rebanhos Gir e mestiços Gir:Holandês que participam do programa de teste de progênie de touros da raça Gir, coordenado pela Embrapa Gado de Leite (CNPGL) em convênio com a Associação Brasileira de Criadores de Gir Leiteiro (ABCGIL). Um total de 5258 primeiras lactações iniciadas entre 1980 e 1997 foi utilizado para se estimar o valor genético dos touros Gir para a produção de leite.

Os valores genéticos foram estimados utilizando a metodologia dos modelos mistos (HENDERSON, 1963) assumindo um modelo animal individual. O seguinte modelo estatístico foi adotado:

$$
\mathrm{y}=\mathrm{X} \beta+\mathrm{Zu}+\varepsilon
$$

em que y é um vetor que contém as produções de leite das vacas na primeira lactação; X, a matriz de incidência dos efeitos fixos (rebanho-ano, época do parto, composição racial e idade da vaca ao parto na forma de covariável com efeitos linear e quadrático); 
694 Rev. bras. zootec.

$\beta$, um vetor de parâmetros desconhecidos representando os efeitos fixos; $Z$, a matriz de incidência dos efeitos aleatórios; $u$, um vetor de efeitos genéticos aditivos aleatórios dos animais com média zero e variância $A \sigma_{\mathrm{a}}^{2}$, não-correlacionado com o vetor de resíduos; e $\varepsilon$, um vetor de resíduos aleatórios com média zero e variância $\mathrm{I}_{\mathrm{e}}^{2}$. A é a matriz dos numeradores dos coeficientes de parentesco aditivo, I é uma matriz identidade e $\sigma_{\mathrm{a}}^{2}$ e $\sigma_{\mathrm{e}}^{2}$ são, respectivamente, as variâncias genética aditiva e residual.

As épocas de parto consideradas foram: 1 - outubro a março e 2 - abril a setembro. Para a composição racial, consideraram-se os seguintes grupos: $0=$ animais Gir, $1=1 / 8$ Holandês:7/8 Gir, $2=$ 1/4 Holandês:3/4 Gir, 3 = 3/8 Holandês:5/8 Gir e 4 = 1/2 Holandês: $1 / 2$ Gir.

Os valores genéticos preditos dos animais foram estimados usando-se os programas MTDFREML (BOLDMAN et al., 1995), que adotam o método da máxima verossimilhança restrita, com algoritmo livre de derivações, para estimar os componentes de variância, e utilizam as equações de modelo misto para predizer os valores genéticos, substituindo os valores paramétricos dos componentes de variância por aqueles estimados via máxima verossimilhança restrita.

A confiabilidade (BOLDMAN et al., 1995) para cada valor genético predito foi estimada por:

$$
\mathrm{REL}=\sqrt{1-\frac{\mathrm{PEV}}{\hat{\mathrm{O}}_{\mathrm{a}}^{2}\left(1+\mathrm{F}_{\mathrm{A}}\right)}}
$$

em que FA é o coeficiente de endogamia do animal, cujo valor genético está sendo predito; $\mathrm{PEV}=\mathrm{C}^{-1} * \mathrm{k}$, em que $\mathrm{C}^{-1}$ é a inversa da matriz de coeficientes das equações do modelo misto (C); e k é um vetor de mesma ordem da matriz $\mathrm{C}$, com 1 na linha correspondente ao animale 0 nas demais linhas. $\mathrm{Na}$ realidade, para estimar $\mathrm{PEV}$, não se inverte a matriz C, mas a solução é obtida pelo mesmo processo de estimação do valor genético dos animais usando a decomposição de Cholesky da matriz C. As PTAs foram obtidas dividindo-se por dois os valores genéticos preditos.

O modelo 1 foi utilizado em três subconjuntos de dados:

1) subconjunto GIR, contendo 4178 lactações de vacas puras Gir, filhas de 486 touros;

2) subconjunto MEST, contendo 1080 lactações de vacas mestiças Gir:Holandês filhas de 51 touros Gir; e
3) subconjunto GIR + MEST, contendo 5258 lactações de vacas puras e mestiças filhas de 486 touros Gir.

Quando as avaliações dos touros basearam-se nos subconjuntos 1 e 3 , a matriz de parentesco continha todas as informações disponíveis do pedigree de cada indivíduo. No caso do subconjunto 2 , a matriz de parentesco continha apenas a relação de pai com filha. Uma quarta alternativa do cálculo das PTAs foi a formação de um índice obtido pela combinação das PTAs estimadas nos subconjuntos 1 e 2, por intermédio da ponderação das PTAs pelas suas respectivas confiabilidades. Assim, as quatro alternativas para se obterem as PTAs dos touros Gir foram denominadas como GIR, MEST, GIR + MEST e ÍNDICE.

Para se avaliar a relação entre as PTAs dos touros e o desempenho de suas progênies puras ou mestiças, o seguinte modelo foi utilizado:

$$
\begin{gathered}
Y_{i j k l m n}=\mu+R_{i}+E_{j}+C R_{k}+b_{1} I_{1}+b_{2} I_{1}^{2}+b_{3} \\
\text { PTA }_{m}+\varepsilon_{i j k l m n}(2)
\end{gathered}
$$

em que $Y_{\mathrm{ijklmn}}$ é a produção de leite da n-ésima filha do touro $\mathrm{m}$, que pariu no rebanho-ano $\mathrm{i}$, na estação do ano $\mathrm{j}$, pertencente à composição racial $\mathrm{k} \mathrm{e}$ com idade ao parto $1 ; \mu$, a média geral; $\mathrm{RA}_{\mathrm{i}}$, a i-ésima subclasse rebanho-ano; $E_{j}$, a j-ésima época do ano; $\mathrm{CR}_{\mathrm{k}}$, a k-ésima composição racial; $\mathrm{I}_{1}$, a l-ésima idade ao parto; PTA $\mathrm{m}_{\mathrm{m}}$, a PTA do touro $\mathrm{m} ; \mathrm{b}_{1}, \mathrm{~b}_{2}, \mathrm{~b}_{3}$, os coeficientes de regressão; e $\varepsilon_{\mathrm{ijklmn}}$, o resíduo aleatório. Com exceção de $\varepsilon$, todos os demais efeitos foram considerados fixos. As definições das estações de parto e composições raciais foram as mesmas do modelo 1.

Omodelo 2 foi utilizado com as seguintes alternativas:

a) quando as PTAs dos touros foram obtidas com base na produção das filhas puras, $\mathrm{Y}_{\mathrm{ijklmn}}$ era a produção de leite das filhas mestiças destes touros;

b) quando as PTAs foram obtidas com base na produção das filhas mestiças, $\mathrm{Y}_{\mathrm{ijklmn}}$ era a produção de leite das filhas puras; e

c) quando as PTAs foram obtidas por intermédio do índice, $Y_{\mathrm{ijklmn}}$ correspondeu, em uma das alternativas, à produção de leite das filhas Gir e, em outra, à produção das filhas mestiças.

Nas situações em que Yijklmn correspondeu à produção de leite das filhas Gir, o efeito de composição racial foi eliminado do modelo.

Em qualquer uma das alternativas, apenas os touros avaliados com no mínimo cinco filhas em três rebanhos foram considerados nas análises. Dessa forma, foram utilizados 48 touros com 712 filhas Gir, 50 touros com 1076 filhas mestiças e 47 touros com 
1788 filhas Gir e mestiças nas análises com o modelo 2 , respectivamente, para as alternativas $a, b$ e c.

Além das regressões, estimaram-se também as correlações entre as PTAs e as produções de leite das filhas na primeira lactação, à semelhança do descrito em a, b e c e as correlações de ordem (método de Spearman) e de valores (método de Pearson) (CONOVER, 1980) entre as PTAs obtidas com base nas diferentes alternativas.

\section{Resultados e Discussão}

As médias das PTAs ponderadas pelo número de filhas por touro são apresentadas na Tabela 1. Observa-se que a média das PTAs dos touros, quando avaliados com base em suas filhas puras ( $\bar{X}=78 \mathrm{~kg}$ ), foi cerca de quatro vezes maior $(\overline{\mathrm{X}}=20 \mathrm{~kg})$ que a média quando os touros foram avaliados com base em suas filhas mestiças. Essa grande diferença é atribuída, em parte, à maior variabilidade das PTAs (de -144 a $259 \mathrm{~kg} ; \sigma=98 \mathrm{~kg}$ ), quando apenas as filhas puras de um touro são consideradas na avaliação genética. Quando as PTAs foram obtidas por intermédio da análise dos dados em conjunto (GIR + MEST), verifica-se que a média $(\overline{\mathrm{X}}=83)$ foi bem mais próxima da média com apenas as filhas puras, mas a variabilidade das PTAs foi maior ( $\sigma=109 \mathrm{~kg}$ e PTA variando de -218 a $327 \mathrm{~kg}$ ). Embora o modelo (1) utilizado para se estimarem as PTAs nesta alternativa contenha os efeitos de composição racial da progênie, ele não considera a possibilidade de as variâncias dos grupos raciais serem diferentes. A formação do ÍNDICE, por intermédio das PTAs obtidas em análises independentes, além de considerar os grupos raciais, quando os touros foram avaliados com base nas filhas mestiças, também considerou a possibilidade de variâncias diferentes entre os dois subconjuntos de informações das filhas puras e mestiças. Embora o número médio de filhas puras $(\cong 15)$ tenha sido menor que o de filhas mestiças (ミ21), a confiabilidade média das PTAs dos touros com base na produção de filhas puras foi bem maior $(0,71$ versus 0,58$)$. Uma das razões é a diferença na estimativa de herdabilidade, que, para o caso das filhas puras, foi de 0,24 , enquanto para as filhas mestiças, de apenas 0,11 . Outro aspecto que também influenciou a diferença em confiabilidade está associado ao uso da matriz de parentesco no caso das avaliações com base no desempenho de filhas puras. Devido à própria característica dos dados de filhas mestiças, a matriz de parentesco não foi utilizada quando se usou o subconjunto de dados MEST. Quando as PTAs foram estimadas com todo o conjunto de dados (GIR + MEST), a confiabilidade média foi maior $(0,79)$, em conseqüência de maior número de filhas por touro e maior estimativa de herdabilidade $\left(\mathrm{h}^{2}=0,20\right)$ e do uso

Tabela 1 - Número de filhas $(\mathrm{N})$, número de touros $(\mathrm{NT})$, média $(\overline{\mathrm{X}})$, desvio padrão $(\sigma)$, amplitude de variação (AMP) e confiabilidade (REL) para as capacidades preditas de transmissão (PTA) dos touros Gir, com base na produção de leite de suas filhas puras (GIR) e/ou mestiças Gir:Holandês (MEST)

Table 1 - Number of daughters $(N)$ and sires $(N T)$, average $(\bar{X})$, standard deviation $(\sigma)$, range of variation $(A M P)$ and reliability (REL) of predicted transmiting ability (PTA) of gyr bulls, based on milk production of their straightbred (GIR) and/or crossbred Gir:Holstein (MEST) daughters

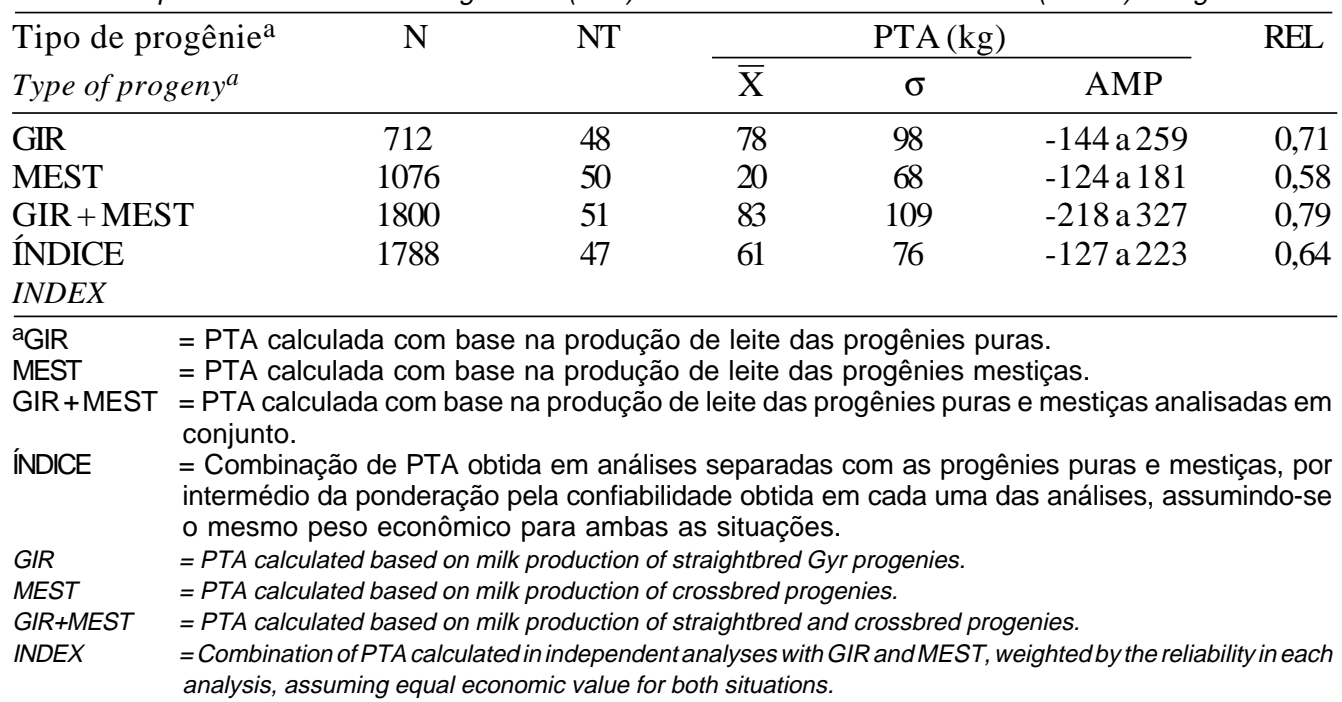


Tabela 2 - Associações da produção de leite, na primeira lactação das filhas, com as PTAs de seus pais

Table 2 - Associations of milk production in the first lactation of daughters with PTAs of their sires

\begin{tabular}{lccc}
\hline $\begin{array}{l}\text { Tipo de progênie } \\
\text { Type of progeny }\end{array}$ & $\mathrm{N}$ & $\begin{array}{c}\text { Regressão } \\
\mathrm{a}^{\mathrm{a}} \text { sobre as PTAs } \\
\text { Regression on PTAs }\end{array}$ & $\begin{array}{c}\text { Correlação } \mathrm{d} \text { com as PTAs } \\
\text { Correlation with PTAs }\end{array}$ \\
\hline GIR & 712 & $0,75 \pm 0,25$ & $0,08(0,10)^{\mathrm{e}}$ \\
& & $2,43^{\mathrm{b}} \pm 0,40^{*}$ & $0,17(0,15)$ \\
MEST & 1076 & $1,54^{\mathrm{c}} \pm 0,30$ & $0,12(0,18)$ \\
& & $1,11 \pm 0,47$ & $0,05(0,19)$ \\
& & $1,60^{\mathrm{b}} \pm 0,32$ & $0,11(0,15)$ \\
\hline
\end{tabular}

a Quando as progênies foram GIR, as PTAs dos touros foram calculadas com base nas progênies mestiças e a regressão foi calculada com as produções das progênies GIR sobre essas PTAs; o inverso quando o tipo de progênie foi mestiça (MEST).

b Regressão das produções de leite das progênies puras ou mestiças sobre as PTAs calculadas por intermédio do índice.

c Regressão das produções de leite das progênies puras ou mestiças sobre as PTAs calculadas com todas as progênies (GIR + MEST).

d Correlação entre as PTAs obtidas com as progênies mestiças com a produção de leite de filhas Gir, e viceversa.

e Correlação esperada, considerando-se a confiabilidade média apresentada na Tabela 1 e os valores de $\mathrm{h}^{2}$ de 0,$11 ; 0,20 ;$ e 0,24 respectivamente, conforme o subconjunto de dados MEST, MEST + GIR e GIR.

* Diferente $(P<0,05)$ do valor esperado (1.0) pelo teste t.

a When type of progeny was Gyr, bull's PTA were calculated based on crossbred progeny and regression was calculated with straightbred Gyr production on these PTAs, the oposite when type of progeny was crossbred (MEST).

$b$ Regression of milk production of straightbred or crossbred progeny on PTAs calculated by the INDEX.

c Regression of milk production of straightbred or crossbred progeny on PTAs calculated using all progenies (GIR + MEST).

d Correlation between PTAs calculated using crossbred progeny and milk production of straightbred Gyr, and vice-versa.

e Expected correlation considering average reliabilities shown in Table 1 and $h^{2}$ values of $0.11,0.20$ and 0.24 , respectively for data on MEST, GIR and GIR + MEST.

* Different $(P<.05)$ of the expected value (1.0) by t test.

da matriz de parentesco com os dados dos rebanhos de gado Gir puro.

Os coeficientes de regressão da produção de leite na primeira lactação sobre as PTAs, assim como as correlações entre a produção e as PTAs, são apresentados na Tabela 2. Os coeficientes de regressão, em geral, foram maiores que o valor esperado. Teoricamente eles deveriam ser iguais a 1,0, visto que as PTAs, assim como as produções das filhas, foram calculadas com base na produção ajustada para o efeito da idade ao parto. O coeficiente estimado de 1,11 , obtido quando as PTAs foram calculadas com base na produção das filhas puras, indica que as produções das filhas mestiças tenderiam a ser ligeiramente superestimadas nesta situação. Contrariamente, observa-se que o coeficiente 0,75 , obtido da regressão com as PTAs calculadas com base no desempenho de filhas mestiças, indica que a produção esperada de leite em filhas puras tenderia a ser subestimada. Todavia, quando as PTAs dos touros foram obtidas por intermédio do índice que considerou a variabilidade de cada subconjunto de dados, verificou-se que, para ambas as situações, as produções das progênies, sejam puras $(b=2,43)$ ou mestiças $(b=1,60)$, foram superestimadas. É importante observar que os coeficientes de regressão $(1,11 \mathrm{e}$
1,60) sobre as produções das filhas mestiças, devido aos seus erros-padrão, não são estatisticamente diferentes do valor teórico esperado. Os coeficientes de regressão $(1,54$ e 1,40) das PTAs obtidas com todas as filhas de um touro, apesar de superestimarem a produção ao primeiro parto de ambas as filhas puras e mestiças, são os que mais se aproximaram do valor teórico esperado, sem diferirem estatisticamente $(\mathrm{P}>0,05)$ de 1,0. Em todas as alternativas, apenas o coeficiente de 2,43 foi estatisticamente diferente do esperado $(\mathrm{P}<0,05)$.

Outra forma de se avaliar a eficiência, ao selecionar reprodutores, é com base no valor genético estimado em informações de determinado grupo de filhas e na resposta produtiva de suas filhas, sejam puras ou mestiças. Esta avaliação dá-se por intermédio da correlação entre a PTA de um touro e a produção de suas filhas. A correlação esperada do genótipo de um touro $\left(\mathrm{G}_{\mathrm{t}}\right)$ com o fenótipo de suas filhas é dada por: $0,5 \sqrt{\mathrm{h}^{2}}$. Todavia, a medida disponível do genótipo é a PTA do touro, que é correlacionada com $G_{t}$ por meio da confiabilidade (REL) da estimativa da PTA. Assim, a correlação esperada do genótipo de um touro com o fenótipo de suas filhas será $0,5 \sqrt{\mathrm{h}^{2}} \times$ REL. Considerando-se as estimativas médias de confiabilidade apresentadas na Tabela $1 \mathrm{e}$ 
as herdabilidades estimadas $\left(\mathrm{h}^{2}=0,11 ; 0,20 ; \mathrm{e} 0,24\right)$, respectivamente, nos subconjuntos de dados MEST, MEST + GIR e GIR, calculou-se o valor esperado da correlação para cada uma das alternativas. Estes valores encontram-se na Tabela 2. À exceção dos coeficientes de correlação $(0,08)$ entre as PTAs obtidas com filhas mestiças com as produções de filhas puras (Gir) e entre as PTAs com filhas puras $(0,05)$ com as produções de filhas mestiças (MEST), os demais valores das correlações foram bem mais próximos dos valores esperados (apresentados entre parênteses na Tabela 2), embora, em geral, menores que estes.

As correlações de ordem e valores das PTAs dos touros, estimadas pelas diferentes alternativas estudadas, são apresentadas na Tabela 3. Os coeficientes de correlação de ordem e de valores entre as PTAs estimadas no subconjunto GIR e as PTA estimadas no subconjunto MEST foram de apenas 0,34 e 0,44 . Todavia, os coeficientes entre as PTAs obtidas com todas as filhas (GIR + MEST) com as PTAs obtidas apenas com filhas puras (GIR) ou mestiças (MEST) foram de 0,75 e 0,79 , respectivamente. Entretanto, quando as PTAs foram obtidas por intermédio do ÍNDICE, observa-se que o coeficiente de correlação foi de 0,94 com as PTAs obtidas com filhas GIR, mas de apenas 0,60 com as PTAs obtidas com filhas MEST. A correlação $(0,91)$ entre as PTA pelo ÍNDICE e as PTA obtidas com todas as filhas (GIR + MEST), embora ambas as alternativas de se estimar a PTA de um touro tenham se utilizado de todas as suas filhas, reflete a diferente variabilidade dos conjuntos dos dados.

Embora na literatura sobre gado de leite apenas dois trabalhos (DIM, 1974; RUVUNA e McDANIEL, 1983) semelhantes a este tenham sido encontrados, os resultados obtidos no presente estudo diferem dos resultados publicados por DIM (1974), que obteve a mesma ordenação dos touros, independente de as avaliações terem sido realizadas com base no desempenho de filhas puras ou mestiças, e por RUVUNA e McDANIEL (1983), os quais concluíram que a seleção de touros com base na produção de suas filhas puras seria efetiva para melhorar a produção de leite das progênies mestiças.

Apesar das discrepâncias observadas entre os poucos resultados encontrados na literatura e os obtidos por este estudo, é importante que alguns dos resultados apresentados neste trabalho tenham discussão mais detalhada. O primeiro ponto que merece atenção é relativo à pequena variabilidade genética $\left(\mathrm{h}^{2}=0,11\right)$ obtida no subconjunto MEST, a qual fez com que as PTAs obtidas fossem muito mais regredidas em direção à zero que as PTAs obtidas no subconjunto GIR. Embora em outros trabalhos, em populações mestiças (FREITAS, et al. 1995; COSTA et al. 1999), tenham sido reportadas estimativas de herdabilidades $(0,08$ a 0,12$)$ de magnitudes semelhantes às obtidas no presente estudo, estes valores são realmente inferiores à grande maioria obtida em populações de animais puros. Existem várias razões que podem ter levado a esta baixa estimativa da herdabilidade. Entre as possíveis causas, destaca-se a pré-seleção das informações, por intermédio da eliminação de lactações curtas (MADALENA et al. 1992), que eliminaria não apenas parte da variabilidade fenotípica, mas também parte da variabilidade genética. Embora não tenha havido nenhuma eliminação de lactações de curta duração neste estudo, a variância genética $\left(55.484 \mathrm{~kg}^{2}\right)$ estimada por intermédio da metodologia REML no subconjunto MEST foi cerca de duas vezes menor que a estimada ( $\left.119.073 \mathrm{~kg}^{2}\right)$ no subconjunto GIR. Todavia, a variância fenotípica total no subconjunto MEST ( $504.400 \mathrm{~kg}^{2}$ ) foi ligeiramente maior que a obtida no subconjunto GIR $\left(496.139 \mathrm{~kg}^{2}\right)$, o que acarretou baixa estimativa de $\mathrm{h}^{2}$ no subconjunto MEST. Dessa forma, parece ser razoável descartar o efeito da pré-seleção dos dados (eliminação de lactações curtas) como responsável pela baixa estimativa de $\mathrm{h}^{2}$ obtida. Outra possível causa de baixa variabilidade genética observada pode ser conseqüência exclusiva do número de reprodutores envolvidos na obtenção dos componentes de variância em cada subconjunto. Já no subconjunto GIR, haviam 486 reprodutores com número médio de oito filhas cada um e no subconjunto MEST, apenas 51 reprodutores com cerca de 21 filhas cada um. Dessa forma, o número reduzido de touros no subconjunto MEST, associado à reduzida quantidade de informação proveniente da matriz de parentesco nesta situação, deve ter sido o principal responsável pela baixa variabilidade neste subconjunto, quando comparado ao subconjunto GIR. Segundo DEMPSTER et al. (1977), a utilização de matriz de parentesco com número reduzido de informações contribui para reduzir o valor estimado da variância genética aditiva. Além destes aspectos, outra possível causa da baixa variabilidade genética poderia ter sido o nível de produção nos dois subconjuntos que poderia limitar a expressão genética dos animais. Todavia, quando se observa que as médias nos subconjuntos MEST e GIR foram, respectivamente, $2442 \mathrm{~kg}$ e $2560 \mathrm{~kg}$, 
Tabela 3 - Correlação de ordem (acima da diagonal) e de valores (abaixo da diagonal) de PTA entre as alternativas utilizadas para se estimarem as PTAs dos touros

Table 3 - Rank correlation (above diagonal) and of PTA values (below diagonal) among alternatives used to calculate bulls PTAs

\begin{tabular}{|c|c|c|c|c|c|}
\hline \multicolumn{2}{|c|}{$\begin{array}{l}\text { Alternativas } \\
\text { Alternatives } \\
\end{array}$} & GIR & MEST & GIR + MEST & $\begin{array}{l}\text { ÍNDICE } \\
\text { INDEX }\end{array}$ \\
\hline \multicolumn{2}{|c|}{ GIR } & 1,0 & 0,34 & 0,75 & 0,94 \\
\hline \multicolumn{2}{|l|}{ MEST } & 0,44 & 1,0 & 0,79 & 0,60 \\
\hline \multicolumn{2}{|c|}{ GIR + MEST } & 0,80 & 0,86 & 1,0 & 0,91 \\
\hline \multirow{2}{*}{\multicolumn{2}{|c|}{$\begin{array}{l}\text { ÍNDICE } \\
I N D E X\end{array}$}} & 0,95 & 0,70 & 0,93 & 1,0 \\
\hline & & \multicolumn{4}{|c|}{ INDEX } \\
\hline a GIR & \multirow{4}{*}{\multicolumn{5}{|c|}{$\begin{array}{l}\text { = PTA calculada com base na produção de leite das progênies puras. } \\
=\text { PTA calculada com base na produção de leite das progênies mestiças. } \\
=\text { PTA calculada com base na produção de leite das progênies puras e mestiças analisadas em } \\
\text { conjunto. } \\
\text { = Combinação de PTA obtida em análises separadas com as progênies puras e mestiças, por } \\
\text { intermédio da ponderação pela confiabilidade obtida em cada uma das análises, assumindo-se } \\
\text { o mesmo peso econômico para ambas as situações. }\end{array}$}} \\
\hline MEST & & & & & \\
\hline GIR+MEST & & & & & \\
\hline ÍNDICE & & & & & \\
\hline GIR & \multicolumn{5}{|c|}{ = PTA calculated based on milk production of straightbred Gyr progeny. } \\
\hline MEST & \multirow{2}{*}{\multicolumn{5}{|c|}{ = PTA calculated based on milk production of crossbred progeny. }} \\
\hline GIR+MEST & \multicolumn{4}{|c|}{$=$ PTA calculated based on milk production of straightbred and crossbred progeny. } & \\
\hline INDEX & \multicolumn{5}{|c|}{$\begin{array}{l}\text { = Combination of PTA calculated in independent analyses with GIR and MEST, weigh ted by the reliability in } \\
\text { each analysis, assuming equal economic value for both situation. }\end{array}$} \\
\hline
\end{tabular}

conclui-se que o nível de produção não deve ter afetado significativamente a variabilidade genética observada no subconjunto MEST. Embora as médias dos dois subconjuntos não tenham sido muito diferentes, em virtude de as filhas puras e mestiças terem produzido, em geral, em rebanhos diferentes, isto pode ter levado à desconexão dos efeitos fixos, que, segundo LALOË et al. (1996), poderia causar um viés nas estimativas dos contrastes aleatórios, ou seja, nas comparações entre as estimativas do mérito genético dos touros. A desconexão dos dados com relação a estes aspectos não foi investigada neste estudo, mas certamente deve merecer análise posterior.

Outra limitação observada que possivelmente afetou os resultados está relacionada ao número ainda limitado de touros (51) que tiveram filhas puras e mestiças produzindo nos diversos rebanhos colaboradores. Todavia, embora parciais, os resultados indicaram alguns pontos que devem ser considerados por ocasião da avaliação genética de reprodutores puros com base no desempenho de suas filhas puras e mestiças.

Considerando-se que o desejável seria a seleção dos mesmos reprodutores, independente de terem sido avaliados com base no desempenho de suas filhas puras e/ou mestiças, e que a produção estimada de suas filhas não fosse viesada, os resultados apresentados sugerem que as PTAs estimadas com base no desempenho de todas as filhas, avaliadas em conjunto ou por intermédio da combinação das avali- ações em separado, serão as mais eficientes na seleção dos touros para uso em rebanhos puros ou em mestiços. No caso das avaliações em conjunto, há o inconveniente de termos correlações de valores e de ordenação menores $(0,70$ e 0,75$)$; no caso do índice, o inconveniente é que a produção estimada das filhas puras será superestimada. Assim, a escolha final de um método ou outro deve basear-se em outras informações, como a importância, para o mercado de sêmen, da indicação correta dos reprodutores para o acasalamento com vacas puras ou mestiças. Nesse contexto, a utilização do índice deveria ser o método de escolha. Todavia, se a necessidade for programar quais filhas deveriam ser selecionadas para produzirem touros jovens para um teste de progênie, certamente a escolha deveria ser para o método que avalia todas as filhas em conjunto, pois não haveria a superestimação das produções e, conseqüentemente, evitaria a seleção errônea de novilhas para a reprodução.

\section{Conclusões}

As avaliações (PTA) com base em informações de todas as filhas, analisadas em conjunto, mostraram-se mais eficientes para se estimarem as produções das filhas, sejam puras ou mestiças.

A seleção de touros avaliados com base em suas filhas puras não resultará na seleção dos mesmos touros, quando estes forem avaliados pelo desempenho de suas filhas mestiças, e vice-versa.

A escolha dos melhores touros com base em suas 
PTAs obtidas com todas as suas filhas puras e mestiças, por intermédio da combinação das PTAs obtidas com filhas Gir e das PTAs obtidas com filhas mestiças, ou com base em suas PTAS obtidas apenas com as filhas GIR resultará na seleção dos mesmos touros, embora as produções estimadas das filhas puras sejam superestimadas no primeiro caso.

\section{Referências Bibliográficas}

ARNOLD, J.W., BERTRAND, J.K., BENYSHEEK, L.L. 1992. Animal model for genetic evaluation of multibreed data. J. Anim. Sci., 70(11):3322-3332.

BOLDMAN, K.G., KRIESE, L.A., VAN VLECK, L.D. et al. 1995. A manual for use of MTDFREML: a set of programs to obtain estimates of variance and covariances. Lincoln: Department of Agriculture/Agriculture Research Service. 120p.

CONOVER, W.J. 1980. Pratical non parametric statistics. 2.ed. New York: John Wiley. 493p.

COSTA, C.N., MARTINEZ, M.L., VERNEQUE, R.S. et al. 1999. Heterogeneidade de (co)variância para as produções de leite e de gordura entre rebanhos puros e mestiços da raça Gir. In: REUNIÃO ANUAL DA SOCIEDADE BRASILEIRA DE ZOOTECNIA, 36, 1999. Porto Alegre. Anais... Porto Alegre: UFRGS, 1999, p.128.

DEMPSTER, A.P., LAIRD, M.M., RUBIM, D.B. 1977. Maximum likelihood from incomplete data via de EM algorithm. J. Royal Stat. Soc. Ser. B., 39:1-38.

DIM, N.I. Progeny testing of dairy cattle on purebreds and crossbreds. In: WORLD CONG. ON GENETICS APPLIED TO LIVESTOCK PRODUCTION, 1, 1974, Madrid. Proceedings... Madrid, 1974. p.669-671.

FREITAS, A.F., WILCOX, C.J., ROMAN, R.M 1995. Genetic parameters for milk yield and composition of crossbred dairy cattle in Brazil. Rev. Bras. Genet., 18(2):229-235.

GREGORY, K.E., CUNDIFF, L.V., KOCH, R.M. et al. 1994. Breed effects, retained heterosis, and estimates of genetic and phenotypic parameters for carcass and meat traits of beef cattle. J. Anim. Sci., 72(5):1174-1183.

GREGORY, K.E., CUNDIFF, L.V., KOCH, R.M. 1995a. Genetic and phenotypic (Co)variances for production traits of female populations of purebred and composite beef cattle. J. Anim. Sci., 73(8):2235-2242.

GREGORY, K.E., CUNDIFF, L.V., KOCH, R.M. 1995 b.
Genetic and phenotypic (Co)variances for production traits of intact male populations of purebred and composite beef cattle. J. Anim. Sci., 73(8):2227-2234.

HENDERSON, C.R. 1975. Comparison of alternative sire evaluation methods. J. Anim. Sci., 41(3):760-770.

HENDERSON, C.R. 1985. Best linear unbiased prediction of non-additive genetic merits in non-inbred populations. J. Anim. Sci., 60(1):111-117.

LALOË, D., PHOCAS, F., MÉNISSIER, F. 1996. Considerations on measures of precision and connectedness in mixed linear models of genetic evaluation. Genet. Sel. Evol. 28:359-378.

MADALENA, F.E., LEMOS, A.M., TEODORO, R.L. 1992. Consequences of removing the variation in lactation length on the evaluation of dairy cattle breeds and crosses. Rev. Bras. Genet., 15(3):585-593.

MEYER, K., CARRICK, M.J., DONNELLY, B.J.P. 1994. Genetic parameters for milk production of Australian beef cows and weaning weight of their calves J. Anim. Sci., 72(5):1155-1165.

RODRÍGUEZ-ALMEIDA, F.A., VAN VLECK, L.D., CUNDIFF, L.V., KACHMAN, S.D. 1995. Heterogeneity of variance by sire breed, sex and dam breed in 200-and 365-day weights of beef cattle from a top cross experiment. J. Anim. Sci., 73(8):2579-2588.

RUVUNA, F., McDANIEL, B.T. 1983. Relationships of predicted differences of dairy bulls and the performance of their crossbred progeny. J. Anim. Sci., 57(5):1133-1137.

VAN DER WERF, J.H.J, BOER DE W. 1989. Influence of nonadditive effects on estimation of genetic parameters in dairy cattle. J. Dairy Sci., 72(10):2606-2614.

VAN VLECK, L.D., CUNDIFF, L.V. 1994. Prediction error variances for interbreed genetic evaluations. J. Anim. Sci., 72(8):1971-1977.

Recebido em: $13 / 08 / 98$

Aceito em: 28/10/99 